\title{
Designed to Fail? the Future of Primary Care
}

\author{
Laurence F. McMahon Jr, MD, MPH ${ }^{7}$ D, Kim Rize, MBA', \\ NiJuanna Irby-Johnson, MD, MBA', and Vineet Chopra, MD, MSC ${ }^{2}$
}

'Division of General Medicine, University of Michigan Health System Ann Arbor, MI, USA; ${ }^{2}$ Division of Hospital Medicine, University of Michigan Health SystemAnn Arbor, MI, USA.

Primary care is widely viewed as being in crisis despite its purported central role in addressing population issues related to healthcare cost, quality, access, and equity. Despite this pivotal role, the nature of the clinical practice today has largely emerged by default. We review the evolution of clinical practice in primary care from its genesis in small practices with paper charts and telephonic patient communication to managed care, pay-for-performance, and today's era of the electronic medical record, value-based payment, and consumerism. We suggest a necessary "reset" of expectations that focuses on today's practice structure and the historic face-to-face patient care expectations. Only by doing so can we successfully meet the demands of patients, society, and practicing internists.

J Gen Intern Med 36(2):515-7

DOI: $10.1007 / \mathrm{s} 11606-020-06077-6$

(c) Society of General Internal Medicine 2020

$\mathrm{P}$ rimary care in the USA has been the focus of every major payment/healthcare delivery innovation over the past 30 years. Access to primary care has been shown to improve patient outcomes and lower cost. ${ }^{1}$ Despite this importance, the interest in primary care and number of medical graduates entering the field has continued to decline. ${ }^{2}$ While much discussion has occurred regarding why this may be so, little attention has been paid as to how the actual clinical day-to-day practice of primary care may explain this trend. Of particular interest is the impact of modern-day innovations on the actual clinical day-to-day practice of primary care providers. In this perspective, we examine the challenges that threaten the future of primary care in the modern era.

The practice of primary care has changed dramatically over the past 30 years. In the 1990s, small private practices with paper charts were the norm. Physicians would interact with patients, handwrite notes and orders, and receive paper reports of tests and consultant recommendations. The communication within the clinic was verbal and outside of clinic by phone or pager. The ethos of the practice was to support the physician,

Received February 25, 2020

Accepted July 17, 2020

Published online July 29, 2020 and out-of-clinic communication was limited to significant clinical concerns. In response to the evolving HMO movement, academic and hospital-centric health systems began to acquire these practices and develop primary care networks. In this context, clinic schedules were designed such that full-time primary care physicians had $32 \mathrm{~h}$ of direct patient contact time and $8 \mathrm{~h}$ to review and chart data. In the parlance of the resource-based relative value scale (RBRVS) system, the $8 \mathrm{~h}$ of activity was the defined pre- and post-work surrounding the actual face-to-face visit with the patient. ${ }^{3}$

As the 1990s progressed, primary care evolved to become the "gatekeeper" in managed care models. Primary care providers became the point of access to specialist and high-cost diagnostic tests, essentially becoming the "speedbump" for patients to gain entry to costlier parts of the organization. The added time explaining this requirement to patients seeking specialty care or advanced imaging and documentation required for the gatekeeper activity was not factored into the practice expectations or compensation plan. As the 1990s ended, the managed care focus and HMOs fell out of favor largely due to dissatisfaction with this approach to cost containment.

In the 2000s, a new paradigm for payment emerged - payfor-performance. The goal of this new paradigm was to reward health systems whose care met or exceeded quality benchmarks and financially punish those who did not. The available clinical quality measures, at the time, focused largely on chronic care management metrics and disease prevention. For chronic diseases such as diabetes, asthma, and congestive heart disease, the focus of many of the performance programs fell again to primary care to provide the service, document its receipt, convince the patient to receive the suggested care, etc. During this period, homegrown electronic medical records began to emerge. These new electronic medical records (EMRs) helped to highlight the receipt of the recommended services and facilitated "scorecards" so that providers' and practices' compliance with quality performance metrics could be measured. Primary care providers were still expected to provide $32 \mathrm{~h}$ of direct patient contact. The fact the data was more readily accessible did, however, change the expectations of patients, specialists, and health system managers. Patients came to expect that the physician would have relevant data within a day or two of a physical visit and would quickly share the results; specialists would expect that follow-up instructions 
could be transmitted directly to the primary care provider, and they would follow the plan and contact patients accordingly; and finally, managers had objective pay-for-performance metrics that could be used to benchmark physicians to national data. These heightened expectations and associated work/ documentation and the faster pace of clinical management and communication were added to the existing workload.

In this evolving milieu, the next decade witnessed three paradigm-altering "innovations" that inexorably changed primary care clinical practice: (1) the modern EMR, (2) valuebased payment, and (3) consumerism. As the structure of the clinical practice of primary care was based on the practice characteristics in the $1990 \mathrm{~s}$, these new practice paradigm changes have coalesced to create the perfect storm that imperils the nature of primary care practice.

To understand the impact of the EMR on primary care practice, we analyzed the 2019 "in-basket" activity of our clinical faculty at the University of Michigan to determine the average weekly activity by category of EMR tasks. A full-time primary care faculty member had a total of 390 inbasket tasks per week or 17,542 in-basket tasks per year. These tasks did not occur in isolation; rather, they almost always led to additional work (such as submitting prior authorizations or communicating with specialists). To understand the time commitment these tasks entailed, we surveyed our primary care physicians and asked how much time, to the nearest minute, they spent on in-basket tasks: of 82 clinicians, 56 responded and reported a median time of $1199 \min (\sim 20 \mathrm{~h})$ per week on these tasks (see Table 1). These findings are not novel: a recent analysis found dramatic differences in the number and type of in-basket tasks by specialty, with primary care having the most tasks per week. ${ }^{4}$ However, these findings clearly demonstrate that current allocated clinical hours $(32 \mathrm{~h}$ of face-to-face clinic time and $8 \mathrm{~h}$ of administrative time) are not enough to maintain our current practice. Rather, these tasks represent the substantial time outside of traditional clinic time that is needed to keep up with current primary care practice demands. In a post-COVID era, the amount of virtual work will only increase and parity and accounting for these efforts is now paramount.

Second, value-based payments have required primary care physicians/practices to manage outcomes for which they were not designed. Added to the 31 pay-for-performance metrics in our practice, outcomes, such as the percent of practice patients seen in the ED for a primary care-sensitive condition or the proportion of discharged patients seen within a week, have left primary care physicians spinning. Facilitated by the EMR, primary care has essentially become the "default" decisionmaker for problems from scheduling to payment, with more members of the health system forwarding issues directly to the primary care physician.

Finally, in the service of consumerism, most labs and test results become available to patients when they are posted to the EMR: day or night. The same patient portal is also used by patients to describe new symptoms, expect an opinion without presenting for a physical visit, or request a prior authorization for a medication. These novel ways of communication - while important for patients - have led to increasing virtual care occurring outside of scheduled patient-physician visits. These EMR e-visits necessitate review of records, messaging patients and specialists to coordinate care and review tests. While progress to reward e-visits in the form of relative value units has begun, conceptualization and incorporation of the burden of this work on daily practice has yet to occur.

These practice changes, coupled with heightened consumer expectations, threaten the survival of primary care because workload does not match hours of practice. Consequently, many physicians opt to work part-time, pursue hospital medicine, or join a concierge practice. Fully, $71 \%$ of our general internal medicine primary care faculty who have practiced more than 3 years now work part-time! In parallel, a growing proportion of our graduating residents choose hospital

Table 1 Electronic Medical Record Tasks per Week

\begin{tabular}{|c|c|c|c|c|c|}
\hline General medicine & $\begin{array}{l}\text { No. per } \\
\text { year }\end{array}$ & $\begin{array}{l}\text { No. per } \\
\text { week }\end{array}$ & $\begin{array}{l}\text { Median time per action } \\
\text { (min) }\end{array}$ & $\begin{array}{l}\text { Median time per week } \\
(\mathrm{min})\end{array}$ & $\begin{array}{l}\text { Median time per week } \\
\text { (h) }\end{array}$ \\
\hline Appointment notification & 37 & 0.8 & 1 & 0.81 & 0.01 \\
\hline $\mathrm{CC}^{\prime} \mathrm{d}$ ED encounter & 283 & 6.3 & 2 & 12.59 & 0.21 \\
\hline Chart completion & 197 & 4.4 & 1.5 & 6.56 & 0.11 \\
\hline Communications & 2383 & 53.0 & 2 & 105.90 & 1.77 \\
\hline Cosign: clinic orders & 2698 & 60.0 & 1 & 59.96 & 1.00 \\
\hline Cosign: encounter & 506 & 11.2 & 3 & 33.72 & 0.56 \\
\hline Letter queue & 7 & 0.1 & 1 & 0.15 & 0.00 \\
\hline Message (non-encounter) & 441 & 9.8 & 3 & 29.37 & 0.49 \\
\hline My open non-visit encounters & 6 & 0.1 & 1 & 0.13 & 0.00 \\
\hline My open visit encounters & 963 & 21.4 & 5 & 107.02 & 1.78 \\
\hline Patient call encounters & 2992 & 66.5 & 5 & 332.46 & 5.54 \\
\hline Patient-entered flowsheet & 8 & 0.2 & 0 & - & - \\
\hline Patient secure messages & 1427 & 31.7 & 5 & 158.52 & 2.64 \\
\hline Result notes & 55 & 1.2 & 2 & 2.45 & 0.04 \\
\hline Results & 3434 & 76.3 & 3.5 & 267.07 & 4.45 \\
\hline $\mathrm{Rx}$ request & 1755 & 39.0 & 2 & 78.01 & 1.30 \\
\hline $\mathrm{Rx}$ response & 94 & 2.1 & 2 & 4.19 & 0.07 \\
\hline Transcriptions & 257 & 5.7 & 0 & - & - \\
\hline $\begin{array}{l}\text { Total general medicine per } \\
\text { CFTE }\end{array}$ & 17,542 & 390 & 40 & 1199 & 20 \\
\hline
\end{tabular}


medicine over primary care, given the certainty and predictability of work. Many also choose concierge practice - where they can control the number of patients they see and avoid the administrative burdens imposed by payors. These options may not be preferred by many; however, they are more viable than the current jobs of primary care practitioners.

How may we bridge this disconnect to save primary care? Several policy and practice changes are necessary. First, health systems must redesign their practices to meet the needs of patients and providers. So-called face-to-face clinical time must be redefined to reflect the reality of practice in today's environment. Our data suggests that a full-time primary care clinician should have 24 (rather than 32 ) h of face-to-face clinical time, with an associated $20 \mathrm{~h}$ of virtual visit and administrative activity. Resetting clinical expectations to reflect the demands of today's practice (and not the practice of the 1990s) would encourage primary care physicians not to work part-time, which has sadly become a necessity to manage the workload that, even at part-time, fills $100 \%$ professional effort in today's era. Second, given the emergence of consumerism, reassessment of reasonable expectations for both patients and providers is necessary. Immediate access to lab results, for example, does little to inform a patient about the meaning of an elevated BUN; consequently, the expectation that physicians will respond quickly to a portal message thus provides little value to the patient. We must ensure that both the patient and the physician benefit by each interaction whether a visit, a secure message, or an email. Third, valuebased payment schemes need to be reconstructed to ensure that clinical outcomes are linked to performance metrics and that the measured value is under the direct management control of the physician. A prime example is hospital readmission which has shown little change even with intensive outpatient management. $^{5}$

Finally, there are other solutions that have been discussed like team-based and virtual care. Such solutions can only enhance the care of patients and rationalize the practice of primary care if they are included in a more comprehensive redesign of primary care. If care teams generate more tasks that find themselves in the physician's in-basket or if virtual care becomes just another task added to the set of expectations in addition to $32 \mathrm{~h}$ of face-to-face time, they will further erode the practice of primary care. The changes in practice resulting from the COVID-19 pandemic have occasioned the exponential increase in virtual care (video/phone). While this new form of care could be added to the "administrative time," when it constituted a fraction of the pre-COVID practice, there is no reason that virtual care would take less time than a face-to-face visit nor generates less in-basket activity. In fact, a virtual visit can lead to a face-to-face visit, occasioning more, not less, total work. Accordingly, virtual visits need necessarily to be included as part of the $24 \mathrm{~h}$ of face-to-face effort and not added to the administrative component of primary care practice. Salary increases that might enhance primary care's attractiveness must first start with creating realistic practice expectations and care team support that will allow physicians to work fulltime. It must be realized that the current practice is that physicians are working full-time in order to complete the tasks expected and are doing that work at a part-time salary.

As we have highlighted, many of the burdens related to advances in payment, documentation, communication, and patient empowerment have fallen disproportionately on primary care without an ongoing assessment of their impact on the day-to-day practice of primary care. Without redesigning our current system and not allowing change by default, primary care will not attract a robust workforce. ${ }^{6}$ In an academic setting, learners witness a workforce that is demoralized and overburdened despite its being touted by many as the linchpin of healthcare reform. Health systems and policy makers must act now to ensure the future of primary care.

Corresponding Author: Laurence F. McMahon, Jr, MD, MPH; Division of General Medicine, University of Michigan Health System Ann Arbor, MI, USA (e-mail: Imcmahon@umich.edu).

\section{REFERENCES}

1. Friedberg MW, Hussey PS, Schneider EC. Primary Care: A Critical Review of the Evidence on Quality and Costs of Health Care. Health Aff. 2010;29(5):766-772.

2. Dalen JE, Ryan KJ, Alpert JS. Where Have the Generalists Gone? They Became Specialists, Then Subspecialists. Am J Med. 2017;130:766-768.

3. McMahon LF Jr. A Critique of the Harvard Resource-Based Relative Value Scale. Am J Public Health. 1990;80(7):793-798

4. Ming T-S, Dillon EC, Nordgren R, et al. Physicains' Well Being Liked to InBasket Messages Generated by Algotithms in Electronic Health Records. Health Aff. 2019;38(7):1073-1078.

5. Dhalla IA, O'Brien T, Morra D, Thorpe KE, et al. Effect of a Postdischarge Virtual Ward on Readmission or Death for High-Risk Patients. A Randomized Clinical Trial. JAMA. 2014;312(13):1305-1312.

6. Sinsky CA, Brown MT. Optimal Panel Size: Are We Asking the Right Question? Ann Intern Med. 2020;172(3):216-217.

Publisher's Note: Springer Nature remains neutral with regard to jurisdictional claims in published maps and institutional affiliations. 